Fecha de recepción: mayo 2014 Fecha de aceptación: mayo 2015 Versión final: julio 2016

\section{Cuerpo, imagen e identidad. Una relación (im)perfecta} Sandra Cornejo *

\begin{abstract}
Resumen: "Como te ven te tratan". Este dicho popular da cuenta de la importancia de la imagen personal y de la mirada del otro en la construcción de la autoestima individual, la identidad y las relaciones interpersonales. ¿Cuál es el rol de la moda y el vestuario en el ajuste/desajuste de la persona en relación a sus pares y círculos de pertenencia? ¿Qué ocurre cuando los cuerpos o la imagen estética se desvían notoriamente del modelo de lo bello actualmente vigente? El asesoramiento de imagen tiene una especial importancia en la génesis de estos conceptos al cuestionar la dupla cuerpo ideal/cuerpo real aportando las herramientas para que cada uno encuentre su lugar particular en el entramado general.
\end{abstract}

Palabras clave: autoestima - cuerpo - ideal - identidad - imagen personal - moda - real vestuario.

[Resúmenes en inglés y portugués en la página 177]

${ }^{(*)}$ Licenciada en Psicología (UBA) con Posgrado en Enfoque Psicoanalítico de los trastornos de la Imagen Corporal. Asesora de Imagen, egresada del Instituto del Profesorado en Lenguas Vivas. Docente en la Universidad de Palermo en la Facultad de Diseño para las carreras de Diseño de Indumentaria y Producción de Moda.

${ }^{(*)}$ Licenciada en Ciencia Política. Asesora de Imagen formada en Francia. Cuenta con un Upgrade in Management, Posgrados en Psicología Positiva, Estrategia, Geopolítica y Retail Marketing \& Loyalty (CRM). Actualmente es miembro fundador VP President de AICI Argentina, Asociación Internacional de Asesores de Imagen con sede en USA. Docente de la Universidad de Palermo junto con Sandy Cornejo y Directora Ejecutiva de CE Imagen.

Ya el dicho popular, "Como te ven te tratan, y si te ven mal, te maltratan" da cuenta de la importancia de la imagen personal tomándola desde su vertiente estética en las relaciones interpersonales.

La conexión entre ambos conceptos es clara a simple vista, ya que según este conocido refrán de la calidad de la primera dependerá el desarrollo de la segunda.

La condición humana de vivir en sociedad implica una influencia insoslayable del entorno en el psiquismo de la persona. A través de las relaciones con los otros se gestarán las más importantes herramientas y características de cada uno de nosotros. La relación con otro es 
la base para la construcción de la autoestima, de la identidad y el desarrollo personal en general, partiendo de ese uno indispensable que es la madre, sin la cual no puede haber vida. Dentro de todos los fenómenos sociales que circundan el devenir del ser humano como tal: política, economía, arte, etc, no podemos negar la importancia de la moda como instauradora de modelos a seguir y como rectora de los límites de lo que es aceptable y lo que no en lo que a apariencia se refiere.

¿Qué ocurre cuando desde su aspecto las personas y sobre todo las mujeres se alejan de este modelo de belleza impuesto externamente?

¿Cuál es el rol del asesoramiento de imagen en este panorama, y hacia adónde nos encaminamos?

\section{Construcción de la imagen personal}

El concepto de imagen personal tiene múltiples aristas que es necesario revisar para comprender la profundidad del mismo y el impacto que tiene en la vida de las personas tanto intra- psíquicamente como socialmente y en su vida de relación.

Todas las personas contamos con una imagen personal formada por diferentes aspectos que incluyen por supuesto las características físicas y netamente estéticas, entendiendo por esto la apariencia general y los detalles que la conforman como el maquillaje, el corte de cabello elegido, los colores predominantes en el vestuario, el aseo, las fragancias, los cortes de vestuario y accesorios, pero sin limitarse a ellos ya que también abarcan aspectos más abstractos como la forma de vincularse con el entorno, los modelos mentales, la filosofía de vida, la ideología y el respeto (o no) a las convenciones sociales. También forman parte de la imagen personal el nivel de lenguaje que se maneja (independiente aunque a veces relacionado con) la formación educativa que ha tenido el sujeto, las costumbres aprendidas en su entorno social y profesional y la postura corporal.

Esta imagen personal es en primera y más importante instancia una comunicación acerca de nosotros. Comunicamos a través de ella y sus múltiples niveles datos sobre nosotros: cómo es nuestro carácter, cuáles son nuestros gustos estéticos, nuestros anhelos, nuestra posición social (real o aspiracional), nuestro carácter, nuestros valores y miles de detalles más. $\mathrm{Al}$ equiparar imagen personal con comunicación, estamos diciendo en conclusión que es imposible no tener una imagen. Se puede tener una buena imagen, una mala imagen, una imagen mediocre, simpática o indeseable. Pero no hay forma de elegir no tener una imagen personal, pública y privada. Pues tenemos una imagen personal hasta ante nuestros propios ojos, relacionada íntimamente con nuestra autoestima y con lo que significamos para nosotros mismos.

La imagen personal además es una de las herramientas que usamos -consciente o inconscientemente- para poder relacionarnos con el entorno y llevar adelante nuestra vida en este mundo. En el mejor de los casos, gerenciamos nuestra imagen a fin de producir los resultados más convenientes para nuestros fines cualesquiera sean: conseguir un trabajo, un 
ascenso, suscitar el interés en otra persona, mantener un círculo de amigos contenedor, etc. En el peor, esta comunicación se produce sin el menor control, quedando a la suerte de cada quien los resultados, a veces buenos, otras, desastrosos.

Y como en toda comunicación, no debemos olvidar el feed-back que vamos a recibir del mensaje que hayamos emitido voluntariamente o no.

Esta devolución desde el exterior va a influir siempre de alguna manera en la gestión de nuestra imagen, sobre todo a nivel emocional y de autoestima porque a través de la respuesta externa corregimos o reforzamos conductas y conceptos acerca de nosotros mismos.

\section{Autoestima}

La autoestima es el sentimiento valorativo de nuestro ser en su totalidad incluyendo los rasgos corporales, mentales y espirituales que conforman la personalidad. Esta autoestima se va gestando desde la niñez, se aprende y se puede modificar. Tiene varias dimensiones: física, afectiva,social,ética yacadémica, quedan cuenta de diversasáreas dedesempeñodelapersona. La autoestima nos indicará la idea, opinión o creencia que tiene una persona sobre su carácter, su personalidad y su conducta, la valoración adecuada o no de lo que tiene de positivo o negativo en todas las áreas tanto físicas como espirituales y hace referencia netamente a la sensación de estar a gusto o disgusto consigo mismo.

Esta sensación a que hacemos referencia es quizás el aspecto más representativo de la autoestima, ya que es la evaluación que llevamos adelante sobre los valores y contravalores que advertimos en nosotros mismos, que produce un sentimiento de admiración, respeto o dolor íntimos con respecto a quiénes somos en relación a quiénes querríamos ser.

La autoestima se gesta, afianza y alimenta a partir de tres pilares:

La significación familiar - El logro de los objetivos - El amor/aprobación de las personas significativas que nos rodean.

En base a la autoestima que poseamos en cierto momento potenciaremos o anularemos nuestra capacidad de desarrollar las habilidades internas o de relación y aumentar así el nivel de seguridad en uno mismo.

El ámbito donde comienza a formarse la autoestima es por supuesto el seno familiar, donde se incorporan los valores, reglas y conceptos. A esto se refiere significación familiar.

Desde muy pequeños incluso antes de nacer ya se tiene en la familia un lugar determinado y que va a comenzar a formar un concepto de cómo nos ven nuestros mayores significativos -padre/madre- el tesorito de la casa, el milagro $y / u$ otras menos favorecedoras y posteriormente el resto de nuestro entorno ampliado, compañeros de juego y escolares, profesores, etc. colaborará a formarla, rectificarla o reforzarla.

Si crecemos sintiéndonos amados y seguros las posibilidades de desarrollar un verdadero sentido de identidad personal aumentan.

Se requiere de la aprobación del otro, la consideración y el reconocimiento del otro para alimentar la autoafirmación. Es en este aspecto que se basa el más tardío deseo de fama, 
honor, que son simplemente la máscara del deseo de reconocimiento del otro y ante nosotros mismos. Sin reconocimiento se sufre, no hay quien pueda desarrollarse con independencia del mismo.

La autoestima de un individuo se forma a partir de los comentarios lenguaje verbal y las actitudes de las demás personas hacia él, que le comunicarán un mensaje acerca de él mismo. Este reconocimiento y cómo se produzca tendrá un papel importante en lo que hace a los desajustes de la imagen en relación a la sensación de bienestar y de la construcción de una relación satisfactoria o insatisfactoria con el propio cuerpo, ya que la autoestima se forma a partir tanto de los comentarios como de las actitudes del entorno hacia la persona.

En relación a la imagen, podemos decir que el nivel de autoestima se relaciona con la percepción de sí mismo en comparación con los valores personales, que son los que se desarrollan durante el proceso de socialización, en la primera infancia.

Se llama caricia a cualquier forma de reconocimiento físico, verbal más allá de que sea positivo o negativo. Una caricia es una manera de comunicar sé que estás ahí y este reconocimiento es fundamental para la vida psíquica, para sentir que uno está bien y es valioso. En la medida que la distancia entre el sí mismo real y el sí mismo ideal es poca, la autoestima es más sana. Cuando esta distancia se agranda la autoestima baja y la persona se siente desajustada y desvalorizada en relación al entorno.

Lo interesante es que esto ocurre muchas veces más allá de la respuesta real del entorno, porque tiene su base en las creencias individuales de cada quien sobre sí mismo, que será lo que permita darle la significación de positivismo o negativismo a las caricias que se puedan recibir de su círculos social, ya que la autoestima constituye un marco de referencia desde donde se interpreta la realidad externa así como las propias experiencias.

La autoestima influye en el rendimiento de la persona, condiciona las expectativas y la motivación y de esta manera se erige en un componente basal en la salud y equilibrio psíquicos. Según un estudio realizado al respecto tal cual se grafica en el esquema a continuación, existe una relación entre la edad y la evolución del auto concepto. En una evolución dentro de los cánones esperables, el niño que se siente valorado y amado por su círculo familiar, comienza con una buena calidad de autoestima, y a medida que se socializa a partir de la escolaridad ésta puede bajar ya que comienza a compararse con otros niños de su edad se enfrenta a otras personas más o menos dotadas que él en diferentes áreas que evalúa desde estética hasta capacidades intelectuales y vinculares. 


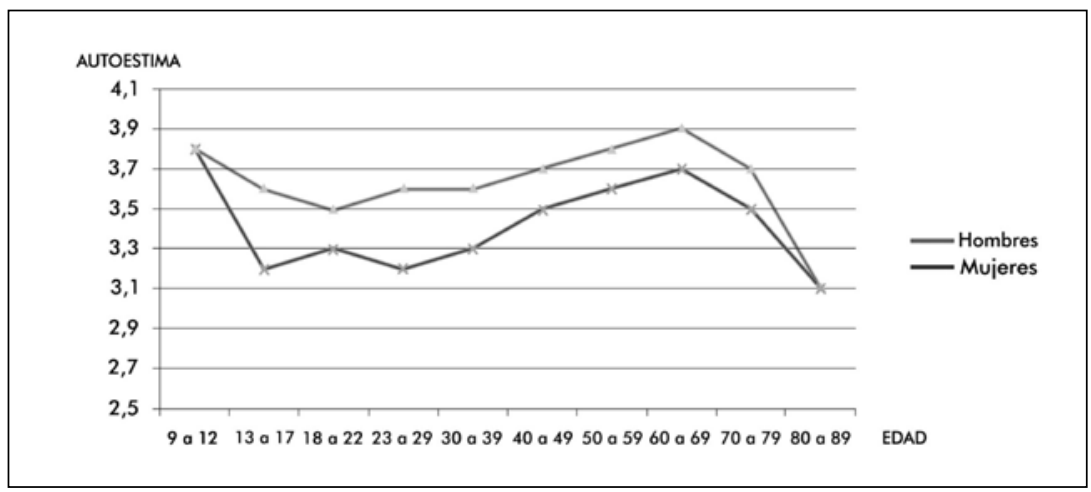

Figura 1. Evolución de la autoestima según la franja etaria. Fuente. Elaboración propia.

Según se expresa aquí, la sensación de ajuste buena autoestima y el consecuente bienestar suelen sufrir un descenso al acercarse a la adolescencia, lo cual no es sorprendente si pensamos que es en ese momento en donde aparecen a nivel evolutivo psicológico, movimientos de re-construcción de la personalidad y la individualidad porque los modelos infantiles ya no sirven y se cuestionan.

Es significativo notar cómo este descenso es más marcado en el sector femenino, impulsado por mandatos culturales de belleza que aún hoy sigue siendo una exigencia preponderantemente femenina. Al entrar en la adolescencia y me atrevo a decir que actualmente en la pubertad y quizás antes comienza para las mujeres la sensación de insatisfacción con respecto a su propio cuerpo.

Esto se traduce en una especie de obsesión en lograr un peso y una forma de cuerpo ideal lo cual es un factor estresante y denostador de la propia identidad, máxime que se realiza sin tener en cuenta las características de forma de silueta y contextura de base.

Si la evolución continúa positivamente se aprecia en el gráfico una suba del auto concepto relacionado sobre todo con el logro de metas, ya que coincide con las edades en donde es esperable que la persona logre el desarrollo profesional logrando la satisfacción personal en el éxito laboral así como en los logros de vínculos afectivos y amorosos por una maduración psicológica y afectiva, volviendo a caer el nivel del auto concepto al aproximarse la vejez, al percibir las pérdida de habilidades consecuentes con esa franja etaria.

Algo especialmente interesante y particular de esta época es la existencia de las redes sociales, internet y la cultura de la exposición que amplía la mirada del otro a ámbitos antes inaccesibles. Cuestiones de la vida privada hoy trascienden a la vidriera virtual exponiéndonos a las miradas y opiniones de miles de personas desconocidas. Este grado de exposición influye en nuestra percepción de éxito/fracaso al compararnos con pares indiscriminadamente, generando ansiedad y frustración, sin evaluar si los ejemplos con los que nos comparamos son los adecuados. 
Recordemos que el segundo pilar en que se apoya el sostén de la autoestima es el amor de las personas, tomando en este caso la máscara de la aprobación del otro en general.

Una autoestima bien construida se manifiesta en varias áreas conductuales y actitudinales. La persona con autoestima firme tiene la fuerza necesaria para buscar la superación de los obstáculos, a pesar de que pueda caer en el desaliento. Ante resultados no esperados la frustración no será muy prolongada y será capaz de obtener enseñanzas de estas experiencias. Cuando se goza de buena autoestima, se es autónomo, autosuficiente y seguro de sí mismo, capaz de tomar decisiones y elegir metas que quiere lograr, sin depender de las opiniones o expectativas que otros tengan para con el.

Este ítem es especialmente importante enfocándonos a lo que es imagen personal ya que desde el entorno se le transmitirán ideas de lo deseable, lo que debería lograr, cómo debería lucir, que no siempre se ajustan a la particularidad del individuo.

Si la persona tiene una autoestima con buena base, podrá realizar un análisis crítico de estos puntos y reconocerlos como verdaderos o falsos en relación a su propio deseo, y a lo que es capaz de lograr según las herramientas que posea.

El respeto y el aprecio hacia uno mismo es la mejor plataforma para relacionarse con el resto de las personas en forma saludable.

Como dijimos, es muy importante la participación de los padres en la génesis de la imagen personal del niño, ya que el sentido del propio valor se aprende del núcleo familiar y de los mensajes que ellos transmiten.

Un niño que crece sintiéndose amado y seguro tiene más probabilidades de poseer un sentido alto de la autoestima y de desarrollar una identidad personal positiva.

La forma en que se planta ante la vida y las relaciones una persona que se sabe valorada le permite generar lazos en donde se lo valore, lo cual retroalimenta la autoestima y renueva así el círculo virtuoso.

\section{Construcción de la imagen del cuerpo}

Desde la escuela psicoanalítica se sostiene que la concepción del cuerpo no nos es otorgada per se desde el nacimiento, sino que se va construyendo a lo largo de la infancia. El descubrimiento fundamental radica en concebir el cuerpo no como un descubrimiento que realiza el infante, sino como una construcción que se desarrolla a lo largo de los primeros cinco años.

Este cuerpo se construye por un lado como una identificación en relación con otros cuerpos (la familia, el grupo social, la etnia) pero a la vez, es diferente y tiene sus propias particularidades.

En los primeros años de vida se gestan los aprendizajes primarios, como la expresión de los afectos, la actitud postural, al gestualidad y la mirada, a partir de los vínculos con los adultos significativos.

Se configuran así las bases psicológicas de un concepto de cuerpo -la imagen corporalparticular, única y original. 
En esta construcción es fundamental el reconocimiento del otro, en primer lugar de los padres, a través de la mirada. Dice Francoise Dolto (1984): "Para el niño, el rostro de sus padres que lo miran con amor, es el espejo de su cuerpo en orden". La madre que mira al hijo con amor, confirma que su hijo es el más lindo, y en esa carga de subjetividad comienza también a gestarse el rudimento del auto concepto tal cual expresé anteriormente.

Resumiendo, la imagen corporal es una representación psicológica subjetiva que puede llegar a ser sorprendentemente diferente de la apariencia real tal y como se ve claramente en las patologías alimentarias del orden de la anorexia pero también en mujeres que perciben su cuerpo como con caderas anchas, mucha cola o teniendo pechos pequeños/grandes cuando no es así a la percepción del observador externo.

La imagen corporal es la representación consciente e inconsciente del propio cuerpo a través de tres registros.

Forma: Se refiere a las percepciones conscientes en relación al tamaño y límites corporales. Cuál es el ancho, el alto, el peso y la postura corporal. Cuál es su ubicación en el espacio, percepción del movimiento y superficie corporal accesible a los órganos de los sentidos, esto es, que se captan a través de ellos.

Contenido: En este ítem entran las percepciones interoceptivas y propioceptivas y cenestésicas de hambre/saciedad, tensión/distensión, frío/calor; dolor, cansancio, etc.

Significado: el plano más inconsciente que corresponde al cuerpo erógeno y las representaciones del deseo subjetivo e individual, la capacidad de comunicar y simbolizar y crear relaciones vinculares con el entorno.

La imagen corporal está íntimamente ligada a la autoimagen, a la autoestima y al sentimiento de sí o identidad, en tanto el cuerpo como tal y la imagen que se forma en el psiquismo de dicho cuerpo, formarán parte de la identidad personal y social del sujeto.

Permite que tome conciencia de sí mismo, de su lugar en el mundo y en relación con los otros.

Y simultáneamente, interactuando con los otros se nutre de contenidos simbólicos y significativos que le permiten interpretar el propio cuerpo retroalimentándose.

A partir de esta premisa, es claro que los valores y significados que la cultura transmite es más que relevante para la formación de la vivencia de ese cuerpo como siendo valioso sólo en tanto delgado, joven y sexuado por supuesto con las diferencias inherentes a las normas genéricas correspondientes a cada uno de los sexos.

En la adolescencia se produce un revival de los procesos de identificación, y se plantea una reorganización de la imagen corporal basamento fundamental de la autoestima impulsado por los cambios físicos y fisiológicos que se producen en esta etapa. La necesidad además de salir de la posición infantil y generar la identidad propia y adulta, hace que la interacción con los grupos de pares cobre relevancia para lograr esta identidad siempre en el marco de las exigencias culturales de la comunidad a la que pertenecen, lo cual orienta hacia los roles que deberá ocupar el sujeto.

Los modelos culturales proveerán de símbolos y ejemplos que marcan el cuerpo desde lo estético, ético y sexual, a través de la oferta de imágenes ideales a las cuales el/la joven pueda identificarse, ya que los de origen ya no sirven. 
Quiero decir con esto que el sistema de valores relativos al género masculino o femenino se presenta como el ideal a alcanzar para obtener así una sensación de bienestar y ajuste social. Y la forma en que cada quien vivencia su imagen corporal, estará íntimamente ligada a las experiencias de reconocimiento del otro, padres, escuela y medios de comunicación, en su aceptación o rechazo, porque ellos transmiten los valores y normas que rigen al grupo. A través de las relaciones con el entorno, se incorporan los valores, características y actitudes que forman parte de la identidad personal, y conforman el modelo de belleza y atractivo sexual, por supuesto diferentes para cada uno de los sexos.

Los modelos culturales de belleza femenina de hoy en día exigen una altura, un peso y un aspecto en muchos casos inalcanzables por lo irreales, ya que están conseguidos a fuerza de cirugías plásticas y photoshop, y basados en cierto tipo de proporciones y contextura no compartidas por todas las personas, sino sólo por un escaso porcentaje de la población.

Lo interesante de este punto es que esta idea funciona en una duplicidad perversa, ya que si bien aparentemente las mujeres sobre todo, pero también algunos hombres son conscientes de que las fotos y las ofertas de modelos femeninos son trucados por llamarlos de alguna manera, su repetición a través de los diferentes medios de comunicación gráfica los hacen parecer ante el psiquismo como reales y posibles de alcanzar, con la consecuente frustración cuando eso no ocurre.

Me resulta preocupante el efecto sobre todo en la adolescencia, ya que si hubo conflictos en la formación de la autoestima basal éstos salen a la luz apoyándose en este caso en la mirada aprobatoria o desaprobatoria no ya de las figuras parentales ya no valoradas sino de sus pares y referentes exogámicos que vienen a suplantar a éstos en el esperable camino hacia la diferenciación y crecimiento individual.

En esta etapa evolutiva, la presión de estos modelos ideales puede llegar a afectar gravemente a quienes están en esta situación de vulnerabilidad.

Y es un observable que esta presión afecta con mucho más a las mujeres, que tienen el mandato social de ser jóvenes, delgadas, bellas que a los varones cuyo mandato apunta más al éxito económico, fortaleza, potencia aunque estos paradigmas están cambiando, aún se sostienen.

\section{Imagen personal, cuerpo, $\mathrm{y}$ mandatos sociales}

Es claro que la subjetividad está en interacción constante con la sociedad, por lo que los fenómenos y situaciones que se presentan en un área, repercute en la otra.

La sociedad marca claramente si bien a nivel inconsciente las pautas de qué se espera tanto de hombres como de mujeres

La transmisión de estos mandatos sociales se produce a través de mensajes publicitarios, de programas difundidos a través de la televisión y medios gráficos que participan de lo cotidiano de la vida de las personas. 
Dije anteriormente a nivel inconsciente porque estas pautas se transmiten a través de mensajes donde se asocian ciertos estereotipos estéticos a conceptos de éxito, dinero y ser deseable, no manifiestamente.

Si bien los estereotipos de belleza cambian a lo largo del tiempo, en relación estrecha con las coyunturas sociales e históricas, desde tiempos inmemoriales se le pide a la mujer que sea bella con los cambios que este concepto ha tenido de la antigüedad hasta nuestros días. En la actualidad estamos ante un mensaje en donde se exacerba la estética y se la valora incluso por encima del talento o conocimiento que la persona pueda tener.

Esto se observa claramente por ejemplo, en los programas de TV, donde los protagonistas son con frecuencia interpretados por actrices y actores que físicamente cumplen con los requisitos estéticos del momento, independientemente de la calidad de su actuación y la existencia o no de talento.

En lo que hace al mundo de la moda y las producciones gráficas asociadas a la misma, también se observa este fenómeno en la elección y exposición de modelos de pasarela con una clara deficiencia de peso, y también en la propuesta de prendas con un tipo de diseño que no quedarían bien en cuerpos más rollizos, y en un orden más comercial en la falta de talles para ciertas prendas, por lo menos en Argentina.

Los mandatos sociales no solamente apuntan a la estética, también como generalidad se presenta la idea de que una persona exitosa y feliz debe poseer bienes materiales costosos (autos, celulares, etc.) así como la popularidad, el reconocimiento y la fama... no así el prestigio.

Aspectos que están relacionados ya que se presentan asociados las figuras de delgadez y el éxito y fama.

Estos ideales de belleza física, éxito y felicidad, influyen en todas las personas, pero tienen un impacto especial en los y las adolescentes, pues es precisamente la adolescencia cuando se realiza una re-construcción de la identidad, centrándose en

gran medida en la re-construcción de la propia imagen.

El adolescente -por la etapa vital que está recorriendo- busca especialmente el reconocimiento y la aprobación en la mirada del otro. Por eso la preocupación de cómo se ven y la pregunta sobre si son suficientemente atractivos se escuchan permanentemente.

Debido al culto actual que se le brinda al cuerpo y al aspecto físico, los y las adolescentes pueden llegar a pensar que si no consiguen y proyectan una buena apariencia, podrían ser rechazados, lo que les impediría alcanzar éxito social.

Cabe aclarar que en algunos casos, esta creencia se extiende y permanece incluso en la edad adulta sobre todo en el género femenino. La imagen se convierte de esta manera en un aspecto de vital importancia para el establecimiento de las relaciones con los demás, a partir de las variaciones de la autoestima.

Creo que es importante revisar con detalle y en forma crítica los modelos que se transmiten actualmente, sobre todo en aquellos productos que van dirigidos a la franja etaria de la adolescencia y preocupantemente, en la infancia y pubertad donde ya comienzan a aparecer los primeros signos de discriminación a ciertas características, como color de piel y peso, predominantemente. 
El peso psicológico que tienen estos estereotipos de belleza/éxito y el esfuerzo en esta etapa por ajustarse a los mismos puede llevar a desarrollar conductas autodestructivas o por lo menos riesgosas, como dietas incontroladas y trastornos alimentarios, ejercicio excesivo, consumo de esteroides y otras sustancias.

Sólo al analizar críticamente estos modelos o ideales se percibe que los mismos están basados en estereotipos irreales y muchas veces irrelevantes, el dinero, la posición económica, el peso, etc. en relación a los valores importantes para el ser humano. Entran en contradicción con los ideales que se intenta enseñar desde la moral y el humanismo, como la cultura del trabajo, la importancia de la bondad, el altruismo, etc. y de este choque sale afectada la autoestima, sobre todo en personas en formación.

Llegado este punto es donde quizás más evidentemente se ve el poder de la imagen personal como medio de comunicar nuestras virtudes y defectos, nuestra personalidad.

La exagerada y casi ilimitada exposición a la que hoy día debemos hacer frente requiere una reflexión profunda acerca de cómo gerencia cada uno de nosotros la imagen propia. Sostenida por la autoestima sana se proyectará una imagen personal bien comunicada, y en este espacio se generan actitudes de fortaleza y se transforman debilidades en aspectos positivos. La doble pregunta: ¿Cómo me veo, cómo deseo que me vean? cobra aquí una relevancia altísima.

Trabajar la imagen externa es una manera operativa de lograr que la brecha entre quién soy y quién aparento ser y cómo me ven se angoste, logrando un mayor nivel de autenticidad y de satisfacción consigo mismo y el consecuente aumento o fortalecimiento de la autoestima. Es además, una buena herramienta para que se produzca una reflexión y un cuestionamiento sobre los modelos reinantes en la actualidad a nivel cultural y social para comenzar a generar un cambio en los mismos.

No es novedad que uno de los canales que esta búsqueda de aprobación transita es el de moda en todas sus vertientes, no sólo el vestuario. La moda impone, coacciona, indica lo que está bien o no. Y divide a las personas entre los que se ajustan a ella y los que no, por lo menos desde una primera mirada, quizás superficial.

\section{Cuerpo, imagen, moda}

Llegada la adolescencia cobra fuerza el deseo ambivalente y compartido por los seres humanos en general, de $c o(n)$-fundirse con el grupo social al que se pertenece o ambiciona pertenecer y a la vez destacarse individualmente por la originalidad o las particularidades personales. Como mencionamos, este deseo no es privativo de esa etapa, pero es en esa edad donde se manifiesta más virulentamente, porque al estar los jóvenes en tránsito a afirmar la propia individualidad y personalidad se encuentran en un momento de reflexión sobre quiénes son, que buscan, y de autoevaluación que pone en juego valores, objetivos y autoestima $\mathrm{Y}$ al tener menos herramientas para definir cuestiones internamente, se apoyarán en el entorno, encarnado por pares y modelos a seguir. 
En esta etapa es donde la moda puede comenzar a aparecer como una forma de satisfacer ambas necesidades psíquicas: por un lado ofrece un conjunto de propuestas claras que pueden ser seguidas con facilidad por quienes lo deseen, incluyéndolos de esta manera en un grupo, el grupo de los actualizados a la vez que propone la posibilidad de destacarse a partir de la diferencia de contenidos de un año a otro o de una temporada a la otra o bien al proponer variantes entre las que el usuario puede elegir a fin de ser original pero siempre, claro, dentro de las tendencias existentes.

No olvidemos que según Giorgio Lomazzi:

La moda como la del vestir, es ante todo un sistemas de signos significantes, un lenguaje: el modo más cómodo pero también más importante y el más directo que un individuo puede utilizar cotidianamente para expresarse más allá de la palabra (Lomazzi, 1972).

A través de la adhesión a la moda, se intenta respetar las reglas del grupo al que se pertenece, o al que se desea acceder. Es interesante ver cómo cuando la integración al grupo es lo suficientemente intensa, las normas o los dictados de la moda están tan asimilados dentro del mismo que crean a sus integrantes la ilusión de estar en plena libertad de elegir qué prendas o tipologías usar, de crear una moda propia.

Un ejemplo claro en la actualidad es la elección por la delgadez extrema y el aspecto deportivo por partes de las mujeres de cualquier edad y contextura, sin tener en cuenta las propias particularidades. La belleza y el ser deseada va de la mano de una delgadez extrema, firmeza en la musculatura y en la piel y mantenerse joven.

Este modelo irreal del que hablábamos anteriormente, impuesto culturalmente a través de la comunicación de medios variados, es aceptado y validado por el segmento femenino en su totalidad.

De esta manera vemos cómo mujeres de cualquier franja etaria se esfuerzan diariamente en dietas, ejercicio físico, tratamientos rejuvenecedores y estéticos más o menos agresivos a fin de mantener el aspecto marcado por nuestra cultura, donde se ha impuesto la noción de que la delgadez es valiosa y respetable. Aún a costa de su propia salud o infelicidad. Porque el alejarse de estos modelos generalmente en forma involuntaria es rechazado por el grupo y estigmatizado, con el consiguiente impacto negativo en la autoestima.

Encuentro que lo interesante de esta concepción es la creencia y convencimiento de que las mujeres aceptan esta imposición por propia voluntad.

$\mathrm{Al}$ respecto es muy interesante la comparación que hace Bryan Turner a propósito de las similitudes entre el ansia de delgadez y el imperio del corset. Dice:

El corset del s. XIX y la manía del s. XX por la delgadez conseguida con la dieta y el ejercicio regulares aseguran que las mujeres se ajusten a ciertas normas de belleza que se presume son atractivas a los hombres. En e este sentido, éstas últimas ilustraba la naturaleza sumisa de las mujeres en una sociedad organizada alrededor de valores e instituciones patriarcales (...). El cuerpo delgado es el camino de una mujer hacia los brazos, el corazón y 
el hogar de un hombre. El corset era, cuando menos, una condición necesaria para el éxito en el mercado matrimonial (Turner, 1989).

Si bien actualmente el matrimonio no está quizás en primerísimo primer lugar en los valores de las mujeres, el cuerpo delgado y modificado a fuerza de cirugías plásticas sigue apareciendo como el pasaporte a "todo lo bueno" de la vida: amor, éxito, dinero, felicidad y la aceptación social.

Un papel importante en la formación de la idea de cuerpo perfecto/irreal lo tiene la difusión indiscriminada de la aplicación del photoshop a casi la totalidad de las producciones gráficas. Pieles idealmente doradas, arrugas desaparecidas, marcas y pliegues borrados van dando lugar de a poco a una idea de cuerpo incorruptible como si esto fuera lo esperable y natural. En este marco, son pocas las personas -sobre todo mujeres- que se acepten o tengan una mirada positiva sobre sí mismas independientemente de lo bien que se encuentren en relación a lo esperable a la edad que tengan, biológicamente hablando. La imagen personal está de esta manera distorsionada por el bombardeo constante que sufren las mujeres desde los medios de comunicación, y también desde los modelos impuestos desde las pasarelas. Es de esta manera que se va formando entre cuerpo, imagen e identidad una relación imperfecta. El cuerpo es negado en su biología, no se acepta envejecer, ni engordar, ni tener marcas, en pos de una imagen ideal del mismo que nace mentirosa, de la fantasía. Se corre detrás de una imagen estética que no tiene en cuenta la particularidad de cada sujeto ni siquiera las posibilidades dadas por la genética. Y esto provoca sufrimiento. Impacta directamente en la autoestima.

¿Cuál es el camino a seguir, entonces? ¿Cuál es la meta, el objetivo trascendental de nuestro trabajo en tanto asesores de imagen?

La transformación pasará por dejar de intentar que el cuerpo y las personas se ajusten a un modelo predeterminado en el cual debe encajar bajo apercibimiento de desvalorización a lograr un cuerpo en armonía consigo mismo y con el medio circundante, tanto social como natural. De valorar las diferencias y la riqueza que aportan a las relaciones y al mundo como tal.

Lo expresa muy bien Susana Saulquin al referirse a la tendencia de los vestidos con intervención de la tecnología:

... disminuídas las presiones sociales en la nueva configuración cultural, las relaciones se darán entre personas más atentas a sus propios requerimientos que buscarán marcar su heterogeneidad y por lo tanto su identidad en sus cuerpos y objetos. La autenticidad como nuevo valor social indicará que el mejor cuerpo será aquel que corresponda a la conformación natural de cada persona. El atractivo de un cuerpo no estará en su delgadez sino en la imagen que represente su salud [...] (Saulquin, 2001).

La diferencia más importante entre una forma cultural y otra en la manera de percibir las interacciones entre la identidad, el cuerpo y los objetos, incluido el vestido, es que en la sociedad post-industrial los objetos con la superioridad que le conferían sus múltiples funciones, resolución de necesidades reales y simbólicas, han llegado como dice Baudri- 
llard a tener la disposición de desempeñar el papel de sustitutos de la relación humana[...] el vestido totalmente manipulado desde el sistema de la moda, presentaba durante la sociedad industrial, transformaciones formales estéticas que respondían más a las leyes del consumo que a la comodidad y confortabilidad de sus portadores. En cambio con la recuperación del vestido como rito individual y la aparición de prendas inteligentes, la novedosa relación cuerpo-vestido se dará a partir de una diferente significación de la noción de cuerpo y de objeto-vestido. Si se utiliza la prospectiva para imaginar el escenario social en la primera década del siglo XXI, se comienza a percibir los cambios sutiles que indican la conformación de un imaginario generado a partir de las necesidades y deseos de las personas individuales, que se orientarán hacia el entorno social y natural. El intercambio cuerpo-vestido no significará para nada la completa fusión de ambas entidades, por el contrario se entablará una relación muy íntima pero con cierta independencia $[. .$.$] en este caso particular el vestido, puede también satisfacer necesidades concretas y$ deseos conformados desde lo psico-social.

(..) un vestido diseñado a partir de nuevos materiales que regule junto al cuerpo la temperatura del ambiente... son objetos con una cierta autonomía, pero deberán responder a un cuerpo que ha potenciado su sensibilidad, para interactuar de manera eficaz con ellos (...) (Saulquin, 2001).

La ceremonia de revestir el cuerpo, ese espacio íntimo de comunión con uno mismo que provoca el enlace con el yo profundo, se ha producido en la sociedad industrial y post-industrial únicamente en los momentos rituales: el traje de novios, el traje blanco de la primera comunión, la mortaja que reviste el cadáver, cumplen una función casi religiosa, ya que re-ligan al origen. Para la sociedad occidental que desde el comienzo de la era moderna había armado categorías independientes para el espíritu, el cuerpo, los hechos sociales, el vestido como tal, y la naturaleza, es indudable que el impacto de los adelantos tecnológicos textiles, permitirán perspectivas diferentes de acción en el sistema de la moda. El vestido diseñado y construido a partir de nuevas tecnologías como un adaptador dinámico de las relaciones entre el cuerpo y el medio ambiente, podrá cumplir con eficiencia esa misión al construirse con materiales que van a potenciar la sensorialidad humana. Si hasta el presente el vestido de moda impactaba sólo al sentido de la vista, la presencia en el diseño de los llamados nuevos materiales que se manipulan para conseguir propiedades específicas, permitirá la expansión sensorial necesaria para se cumpla la correcta interacción entre cada persona y su medio. En la actualidad la funcionalidad del vestido se acentúa de tal manera, que la forma de definir un material es indicar las prestaciones que puede dar. Esto ocurre así porque en esta sociedad globalizada y acelerada, la vestimenta comienza a resignar la función principal de indicador social a favor de cumplir con los distintos requerimientos para la cual fue diseñada. No resulta difícil comprender entonces el sitial de privilegio de los nuevos materiales que serán capaces de responder al nuevo imaginario social organizado a partir de los cuidados ecológicos tanto humanos como ambientales. Respuesta eficaz para diseñar las prestaciones específicas por propiedades que surgen al combinar materiales que van a estar en contacto permanente con un cuerpo al que cuidarán y protegerán. Resulta interesante 
descubrir como los nuevos materiales inteligentes desarrollados en el contexto del gran avance tecnológico y por lo tanto orientados hacia el futuro, promuevan al mismo tiempo la recuperación del sentido primitivo y original de un cuerpo en armonía con el universo.

\section{El asesoramiento de imagen}

Pienso que es fundamental en la tarea del asesor de imagen que éste sea consciente -para luego concientizar a su cliente- de que se está ofreciendo desde lo cultural un modelo que no existe como real y posible.

La función del asesor de imagen es, en última instancia, recomponer esa relación imperfecta, reacomodar los conceptos de cuerpo, imagen e identidad para que convivan más armoniosamente a partir de la aceptación de las propias particularidades, la concientización de los defectos pero también de las virtudes que se poseen.

Al trabajar con el cuerpo real y mostrar al cliente sus partes positivas, y ponerlas en valor, se contribuye a aliviar esa tensión que surge de la enorme diferencia que hay en algunos casos entre la imagen real y la imagen ideal de sí mismo.

Es innegable que el aspecto de cada quien es la tarjeta de presentación que puede abrirle o cerrarle puertas al logro de objetivos variados.

La imagen estética, la imagen personal no sólo en su vertiente de vestuario, maquillaje y peinado sino también en la de oratoria, relación con el entorno, modales, es el catalizador de las características internas.

A través de una imagen trabajada se puede transmitir nuestros talentos, lo cual es innegablemente positivo en el momento que nos toca vivir, donde la comunicación está en un lugar privilegiado.

Ese es el concepto que debe subyacer al asesoramiento de imagen, desde mi concepción. La imagen personal es una construcción, porque es algo vivo, algo que se crea y se modifica, que proyecta nuestro yo y es, principalmente una comunicación.

Hablamos de nosotros a través de nuestra imagen personal.

Decimos si somos cordiales o agresivos, abiertos o de pensamiento estructurado, contamos nuestros gustos, nuestro nivel educativo, de si nos respetamos. Hablamos de nuestros ideales sin abrir la boca y fundamentalmente, revelamos cuál es el concepto que tenemos de nosotros mismos y nuestra seguridad para llevar adelante nuestras vidas.

También es innegable que el primer impacto de la imagen es visual y de allí, además de la particular coyuntura social y cultural actual la importancia de la apariencia en general y la moda en particular.

La moda propone las reglas y preceptos dentro de los cuales deberían moverse las personas a fin de ser aceptadas y consideradas parte del grupo. Reafirma la pertenencia o no del sujeto al grupo, satisface la necesidad gregaria del ser humano, la necesidad de aceptación y mirada afectiva, de la caricia del otro que es inherente al ser humano y que está presente desde su nacimiento. 
Es remarcable al respecto la concepción de Pierre Bordieu cuando dice:

El discurso de la moda propone la manera de introducir un cuerpo en cierta relación del mundo...Pero la tiranía de la moda supone una entrega del cuerpo a la mirada del otro- encarnado éste en ciertos patrones sociales- y a angustia cuando es imposible transformar la carne en un signo que sea leído de manera adecuada según los ideales de la persona, según la imagen de sí mismo que se quiere dar a sostener por el otro (Bordieu, 1989).

El vestuario comunica, habla de cada quien, como decíamos anteriormente. El problema radica en aquellos casos en que lo que trasmitimos a través del vestuario no tiene conexión con nuestra ética, ideología y filosofía de vida. Cuando nos disfrazamos en lugar de vestirnos, porque el disfraz conlleva una carga de energía psíquica muy grande, como toda mentira, y el precio de sostenerlo es alto.

La moda dictamina el vestuario adecuado. Impone códigos que exigen ser respetados. Estos códigos de vestuario son fluctuantes, sí, pero no por eso menos importantes en sus efectos y consecuencias. Quizás es esa misma fluctuación lo que los hacen tan tiranos, pues requieren constante atención para captarlos y ponerlos en práctica de manera adecuada. $\mathrm{Al}$ respecto, me parece trascendente la siguiente afirmación de Umberto Eco: "La moda no prohíbe. Obliga, coacciona. Y en la historia existen siempre los escandalizados por el mandato de la moda y los angustiados por no poder cumplir dichos mandatos".

En lo personal, me preocupan más los angustiados que los escandalizados. En los escandalizados encuentro que hay un atisbo aunque más no sea de crítica, de reflexión, de cuestionamiento a los mandatos. El escandalizado puede moverse, hacer algo para cambiar o anular aquello que lo escandaliza.

El angustiado suele estar paralizado.

En los angustiados hay sumisión, hay desesperación irreflexiva por sentirse inadecuados, incompetentes para cumplir una función o un deber que es inapelable, incuestionable.

Y este desajuste marca la relación imperfecta entre quienes somos y quienes queremos ser o quienes pensamos que queremos ser.

En los angustiados no hay demasiada reflexión sobre si ese mandato que no se cumple es válido. Si es importante y si debe ser tan universal como se supone.Si existe una universalidad una uniformidad cuando hablamos de la cuestión humana. Se quiere cumplir a cualquier costo, incluso la propia salud, como se ve en los casos de personas con trastornos de la alimentación, más allá del signo que tengan anorexia $u$ obesidad y de la imagen vigorexiaca, adictos al deporte.

Es con ellos con quienes el asesor de imagen tiene campo fértil para su labor, en tanto comprenda que su función pasa por cuestionar las creencias de sus clientes, sobre todo aquellas que resultan inhabilitantes y no son reales. 


\section{Casos especiales}

Para esta altura creo que ya quedó claro que una relación perfecta ideal entre cuerpo, identidad e imagen es un concepto ideal y complejo, y al que se puede llegar sólo a costa de cuestionar el concepto actual de belleza y despegarse de él, valorando las particularidades de cada quien. Se producen en las personas que transcurren una evolución esperable del psiquismo y la identidad, apoyadas por un sentido crítico de los modelos presentados por diferentes medios, sobre todo los ámbitos de moda y medios masivos de comunicación. Pero lo más habitual es que se produzcan traspiés que la convierten en una relación imperfecta, y esto -sorprendentemente- desde temprana edad. Muchas veces esta relación se complica aún más por el desajuste estético que existe en algunas personas, que con su apariencia se alejan mucho del modelo imperante en la actualidad.

Sabemos que este desvío impacta directamente en la autoestima y la imagen personal de aquellos individuos pertenecientes a estos grupos desajustados.

Y dentro de esos grupos, me gustaría hacer referencia a dos ejemplos bien diferenciados pero con algunos puntos en común relacionados con la salud, donde mi experiencia como asesora de imagen ha sido interesante: mujeres con efectos de quimioterapia y mujeres con sobrepeso importante u obesidad.

Si bien son dos situaciones que pueden suceder tanto en hombres como en mujeres, lo cierto es que éstas últimas tienen mayor presión en cuanto a lucir bellas debido al mandato cultural que afecta a ambos sexos y que pone la estética del lado de lo femenino, mientras que en los hombres coloca el poder y el éxito, sobre todo económico.

En ambos casos las mujeres sufren un alejamiento notorio de lo que es el paradigma de belleza y pérdida de la autoestima. La tarea del asesor de imagen a través del trabajo de re-construir esa imagen estética y re- acercarlas de alguna manera a este modelo, tiene como resultado un refuerzo de la autoestima y la consecuente mejora tanto en el estado de ánimo como en la relación del sujeto con su entorno social, al no sentirse como objeto de la mirada reprobatoria o de horror del otro.

Sin embargo, nos encontramos claramente con algunas diferencias En el primer ejemplo: pacientes de quimioterapia este alejamiento tiene la característica de ser temporario dura aproximadamente lo mismo que el tratamiento quimioterapéutico, pero el cambio en la imagen es veloz y aunque la persona sabe lo que va a ocurrir, la extrema rapidez así como la manera en que ocurre la pérdida de cabello y vello corporal es altamente traumática.

No se trata sin embargo, sólo de la pérdida del cabello y vello en general, ya que los tratamientos como la cirugía, la quimioterapia, la radioterapia y los tratamientos paliativos, alteran la piel y la hacen más vulnerable.

Es importante que el paciente aprenda a cuidarse durante, pero también después del tratamiento, hasta que se produce la regeneración de su imagen estética a su aspecto anterior al diagnóstico.

Desde su discurso, las personas que están sufriendo las consecuencias de la quimioterapia arriba mencionados manifiestan sentirse perdidos en relación a su identidad, cuando lo que en realidad está siendo afectado es su imagen, apartándolas de la vida social, resintiendo la autoestima y afectando sus ganas de seguir adelante. 
Es importante despegar el concepto de imagen estética de la superficialidad o de lo superfluo, de la artificialidad.

Creo que la dedicación que se brinda al mantenimiento de la imagen estética, el cuidado por uno mismo es indicador de respeto, de autoestima y de bienestar.

Siendo la imagen estética la carta de presentación de cada persona, la paciente en tratamiento se ve disminuida en su ser, y por lo tanto se apartaban de la vida social, trayendo como consecuencia frustración y en muchos casos soledad, emocionalidad negativa que no ayuda a superar de la mejor manera esta situación momentánea que está viviendo la mujer. Afortunadamente la mayoría de los médicos y psicólogos relacionados con la oncología es consciente de la importancia que tiene el sentirse bien consigo mismo y mantener un buen estado de ánimo para el éxito y el transcurrir del tratamiento, y no dudan en derivar a sus pacientes a un asesoramiento de imagen para trabajar esta situación incluso de manera preventiva.

Aquí la función del asesor será devolver a la paciente el aspecto que tenía antes de padecer los efectos del tratamiento.

Se le explica y orienta para que recupere la forma en que se veía antes de comenzar el tratamiento cuando estaba saludable a través de trucos ópticos que ayuden a disimular los cambios que ocurrieron, más allá de que sean temporarios.

Es una intervención para el durante y también para el después, hasta la total recuperación de la imagen estética.

Lo más complicado en estos casos no es conocer los trucos de asesoramiento que permiten ayudar a estas mujeres con su imagen, sino controlar los aspectos angustiantes que con lleva esta enfermedad y manejar la identificación con el cliente.

Es un trabajo del asesor consigo mismo el que le permitirá poder asesorar o no a las personas que estén atravesando esta situación.

Laintervención sobreestetipodeclientestieneademáselplusdecolaborara reconectarloscon aspectosdelavidacotidianaquemuchasvecessepierdeanteeldiagnósticodeestaenfermedad. Ocuparse de algo considerado frívolo como su aspecto, el hecho de pensar cómo combinar colores, cómo disimular la falta de cejas o de cabello, de recomponer su imagen estética, quita su atención del hecho de estar enfermo y la vuelve a colocar en áreas que tienen que ver con la autoestima, la autovaloración y la vida normal de una mujer.

En el caso de la obesidad, en cambio, tenemos un alejamiento del prototipo de la belleza femenina y masculina con un sustrato de baja autoestima basal en la generalidad de los casos y se trata de un proceso que ocurre en forma lenta y sostenida. Existe además el agravante de que recién en este tiempo existen casas de ropa que pueden ofrecer talles adecuados con algo de diseño y estética en sus prendas a aranceles accesibles. Hasta hace un tiempo la idea era que la persona obesa debía ocultar su cuerpo. De la mano de ciertas campañas -aún rudimentarias-y la aparición de una mayor oferta de vestuario, comienza a instaurarse la idea de que no tiene por qué ser así, y que es válido su deseo de lucir como cualquier otra mujer.

Esta tendencia está en sus albores, pero creo que con grandes posibilidades de pisar firme, ya que no solamente se centra en la obesidad en sí sino en el sobrepeso, que curiosamente muchas mujeres sienten tener, más allá de que esto sea verdad o no. 
Otra diferencia a nivel relacional con el entorno y lo social es que mientras la paciente oncológica recibe una respuesta de compasión por el momento que pasa, la respuesta hacia la persona con sobrepeso se ubica mayoritariamente del lado del desprecio y de la creencia de que esa persona es gorda porque quiere, esto es, se le adjudica completa responsabilidad por su estado, sin tener en cuenta el que psicológicamente suele tratarse de gente dañada y con impulsos incontrolables de ingesta, aunque conscientemente sepan que es dañino para ellas. Existe un componente adictivo en la obesidad.

Podemos considerar a ésta como un síndrome conformado por factores diversos que se interrelacionan y actúan entre sí como la herencia genética, sedentarismo, comer excesivamente, metabolismos disfuncionales y aspectos psicológicos y sociales que son lo que nos interesan a los fines de este trabajo.

En cuanto a los aspectos sociales, en el momento actual la sociedad es obesofóbica-prueba de esto es observar que el calificativo gorda es utilizado muchas veces como un insulto entre mujeres- en donde las personas con esta enfermedad son estigmatizadas y sufren consecuencias en la autoestima recordemos que ésta suele ser frágil de base, dificultad para las relaciones amorosas y para ubicarse en la vida laboral por las connotaciones inherentes a ser obeso para el imaginario social: descontrol, vagancia, flojedad.

Las personas con un sobrepeso grande, sin quizás necesariamente ser obesos por definición, se encuentran viviendo sensaciones de desvalorización a diario, a una presión social importante, que por supuesto cada quien elaborará de acuerdo a sus herramientas psicológicas y estructuras de personalidad. Quien es obeso es juzgado como físicamente menos atractiva, carente de voluntad y conducta, esto lleva a que muchas personas con sobrepeso desarrollen una imagen corporal negativa en la primera infancia que muchas veces se mantiene a lo largo de la vida.

Los medios de comunicación como ya hemos dicho, recuerdan constantemente que para estar a la moda y ser exitoso y deseable hay que estar delgado y socialmente las personas con sobrepeso son el blanco de burlas incluso desde la infancia.

Encontramos en estos casos, que existe una preocupación estresante por la apariencia, más inhibitoria que una simple insatisfacción y la consecuente timidez y vergüenza, cuando esta apariencia es percibida por otras personas, que desemboca en un sentimiento de timidez o vergüenza en situaciones sociales.

Además de la excesiva importancia que se le da a la apariencia física en la autoevaluación, la persona llega a evitar la participación en actividades por vergüenza ante su apariencia y la respuesta negativa que siente desde el entorno.

La insatisfacción con la imagen corporal en la obesidad no solo es una motivación frecuente para intentar bajar de peso sino también puede ser motivo de un importante y significativo impedimento y malestar crónico ya que influye en los pensamientos, sentimientos y conductas repercutiendo además notablemente en la calidad de vida de quien la padece.

Los esfuerzos por ponerse a tono con lo que se supone pide la sociedad de ellas, esto es, una figura esbelta, conllevan también un trabajo psicológico para resolver las consecuencias de llevar una dieta hipocalórica estricta, ansiedad, nerviosismo, irritabilidad y a veces hasta depresión, como también el vaivén dado por los ciclos de pérdida/recuperación del peso, 
o los estancamientos de peso que toman para las personas significación de fracaso y los hacen sentir inadecuados y criticados por su círculo social en general.

En este caso es en donde se ve más claramente la relación imperfecta que existe entre el cuerpo, la identidad y la imagen.

Para el asesor de imagen, este segmento es en donde se ve más comprometido al actuar e intervenir, ya que no solamente está lidiando con la parte más externa y simple de esta profesión como es elegir las prendas y colores y estilos de vestimenta más adecuados para cada persona, que de por sí ya presenta dificultades por la escasez de oferta del mercado sobre todo en lo que es el target juvenil, sino que además debe enfrentarse a una persona muy dañada psíquicamente y con características particularísimas con quien se debe tratar de manera especial para no colaborar con la fantasía de que se lo está juzgando por su apariencia, cuando justamente, se nos convoca para que lo ayudemos a verse mejor.

De ahí la necesidad de una formación integral del asesor de imagen y no solamente en lo que compete a vestuario, maquillaje, peinados y colores. El conocer en profundidad la problemática de base de estas personas, entender el peso que se siente desde la sociedad y los mandatos culturales, se consciente de los medios que se usan para transmitirlos, y poder diferenciar claramente realidad de fantasía (photoshop, cirugías plásticas, cuerpos moldeados a fuerza de dietas insalubres, etc) son prioritarios para el asesor para poder comunicárselo al cliente y ayudarlo a discernirse como particular y valorar los aspectos positivos de sí mismo. En estos casos es cuando con más claridad se ve la función de acompañante emocional que tiene el asesor de imagen y lo valioso que puede ser su aporte solo o en combinación con otros profesionales y/o tratamientos.

\section{Conclusiones}

En la actualidad los modelos estéticos son provenientes de la fantasía. Son irreales en tanto son cuerpos manipulados por diferentes medios, cirugías, photoshop, propuestas de modelos de pasarela y por lo tanto, que llevan a la insatisfacción consigo mismo al no poder cumplirlos.

Estos modelos inciden negativamente porque comienzan su influencia en muy temprana edad, en donde la capacidad de discernimiento está en desarrollo.

Estos modelos estéticos van prioritariamente dirigidos a las mujeres, pero en la actualidad comienzan a verse algunos asomos de exigencias del estilo para los hombres, abdómenes musculosos, brazos tonificados, abundante cabellera y son ellas por lo tanto las más afectadas y las que padecen mayoritariamente trastornos de la autoestima y la imagen corporal. Es preocupante cómo a nivel de la tarea del asesor de imagen, nos encontramos cada vez más con mujeres que no tienen más que un sobrepeso pero se perciben y son percibidas como obesas.

Atender personas con sobrepeso/obesidad implica un trabajo de recomposición de la imagen y la autoestima mucho más arduo que para las mujeres que no entran en esta 
categoría, porque estas personas vienen desde hace mucho tiempo con dificultades para lograr una imagen personal percibida como valiosa, y deberán poder sostenerla durante el resto de su vida.

Es difícil lograr una armonía entre los conceptos de imagen, identidad y cuerpo en tanto no se revean y se modifiquen los modelos de estética que estamos comunicando.

Es necesario promover la reflexión y el cuestionamiento de los ideales imperantes a fin de construir una imagen personal a partir de valores como la libertad, la igualdad y el respeto y aceptación de las diferencias. Estimular conductas que no afecten la salud ni el desarrollo integral de las personas, ayudándolas a sentirse mejor consigo mismas con y no a pesar de sus particularidades.

Apuntando a la valoración la riqueza que se da en la diversidad de tipologías corporales y de etnias con las que cuenta la especie humana, podremos llegar a una relación perfecta y armónica entre el aspecto exterior y el interior de cada quien, logrando de estar manera formar personas más satisfechas consigo mismas y más felices.

Hoy en día la función del asesor de imagen trasciende la de recomendar colores y ropa simplemente. Debe ser un cruzado en la concientización de que los modelos hoy exigidos son imposibles de lograr y en la valorización de los aspectos positivos de cada quién más allá de los imperativos culturales estéticos regentes en la actualidad.

\section{Referencias Bibliográficas}

Bordieu, P. (1989). El cuerpo social. La Distinción. Madrid: Taunus.

Eco, U. (1972). El hábito hace al monje. Barcelona: Lumen.

Estebecorena, M. P. (2011). Imagen y Resiliencia en adultos, II Congreso en Psicología Positiva de la Universidad de Filadelfia, USA 2011.

Lomazzi, G. (1972). Psicología del vestir. Barcelona: Lumen.

Saulquin, S. (2001). El cuerpo como metáfora. Revista DeSignis. Barcelona: Gedisa.

Turner, B. (1989). El cuerpo y la Sociedad. México: FCE.

Zukerfeld, R. (2002). Psicoterapia psicoanalítica y obesidad. Revista Actualidad Psicológica no 300 . 
Summary: "They treat you as they see you" This popular saying reflects the importance of personal image and the look of the other in the construction of individual self-esteem, identity and relationships. What is the role of fashion and costume on the adjustment / maladjustment of the individual in relation to their peers and communities of belonging? What happens when the bodies or the aesthetic image deviate markedly from the current beautiful standard? The image consulting is particularly important in the genesis of these concepts when questioning the ideal body/ real body duet providing the tools for everyone to find their particular place in the overall framework.

Keywords: body - costume - fashion - ideal - identity - personal image - real - self-esteem.

Resumo: O dito popular "como te vem te tratam" mostra a importância da imagem pessoal e da mirada do outro na construção da auto-estima individual, a identidade e as relações interpessoais.

Qual é o papel da moda e do vestuário na sensação de ajuste/desajuste da pessoa em relação a seus pares e círculos de pertença? Que ocorre quando os corpos ou a imagem estética se desviam notoriamente do modelo do belo vigente na atualidade? $\mathrm{O}$ assessoramento de imagem tem uma especial importância na gênesis destes conceitos ao pôr em causa a dupla corpo ideal/corpo real aportando as ferramentas para que cada um encontre seu lugar particular no entrançado geral.

Palavras chave: auto-estima - corpo - ideal - identidade - imagem pessoal - moda - real - vestuário. 